"defenders of the truth" (Segersträle, 2000) have been trying to prevent this, but unless they can offer a more solid alternative, they will not succeed.

Abed, R. T. (2000) Psychiatry and Darwinism. British Journal of Psychiatry, 177, I-3.

Darwin, C. R. (1859) On the Origin of Species by Means of Natural Selection, or the Preservation of Favoured Races in the Struggle for Life. London: John Murray. Republished (1985) Harmondsworth: Penguin Classics.

Rose, S. \& Lucas, P. (200I) Evolutionary psychology revisited (letter). British Journal of Psychiatry, 178, 573.

Segersträle, U. (2000) Defenders of the Truth. The Sociobiology Debate. Oxford: Oxford University Press.

A. Ayton West End Child \& Family Service, 2062-68 Hessle Road, Hessle HUI3 9NW, North Humberside, UK

\section{A defence of community mental health teams}

Dr Holloway's (2001) stimulating, if ever so slightly mischievous, commentary on our paper (Simmonds et al, 2001) adds substance to the debate on this subject but leaves the reader with the unfair impression that community mental health teams are now out of date and have been replaced by 'more exotic fruit'. Indeed, our labours have borne much more fruit than we expected, as Dr Holloway identifies our study as a mélange from a variety of species. We accept that the studies in our review showed great heterogeneity of service provision but all possessed the key central feature in the experimental group, a teambased community service. The fact that we were able to identify only five studies that satisfied the criteria for such a comparison, despite the widespread use of such teams, illustrates the consequences of deciding on policy in the absence of evidence. Once this is done, the subject cannot be researched through adequate randomised studies since policy makes the interventions statutory. Dr Holloway is right in concluding that community mental health teams have become the focus of mental health care in the UK and, although they are now universal here, it is still possible to carry out further randomised controlled trials elsewhere. We are in the process of developing similar studies in Eastern Europe, which should help to provide a stronger evidence base for our conclusions if they replicate the findings in the five studies we reported.
What would be most unfortunate at this stage of development of a community mental health team would be to move on to a new model based on the North Birmingham approach (Peck, 1999) without further evidence. The North Birmingham model has not been tested by any form of controlled comparison and there is now a strong body of evidence, to which Dr Holloway himself is a major contributor (Holloway \& Carson, 1998; Burns, 2000; Tyrer, 2000), which shows the standard community mental health team to be a robust and effective service model that is at least as effective as the new specialist approaches.

To return to the fruit metaphor, our review, and the work of others, seems to have established firmly that apples, grapes and oranges are good for your health when compared with other non-fruit diets. Recently, mangos, paw-paws and persimmons, have also been introduced and have attracted considerable numbers of devotees. To date, these exotic fruits have not proved in any way to be superior in their healthgiving properties than the older fruits; until they do so we should not change our fruit policy. So we should stick with the community mental health team. James Lind, the originator of the first ever controlled trial-of citrus fruit juice for scurvy would not have expected anything less.

Burns, T. (2000) Models of community treatment in schizophrenia; do they travel? Acta Psychiatrica Scandinavica, 102 (suppl. 402), II-14.

Holloway, F. (200I) Invited commentary on Community mental health team management in severe mental illness. British Journal of Psychiatry, I78, 503-509

- \& Carson, J. (1998) Intensive case management for the severely mentally ill. Controlled trial. British Journal of Psychiatry, 172, 19-22.

Peck, E. (1999) Introduction to special section on community mental health teams. Journal of Mental Health, 8, 215-216.

Simmonds, S., Coid, J., Joseph, P., et al (200I) Community mental health team management in severe mental illness: a systematic review. British Journal of Psychiatry, I78, 497-502.

Tyrer, P. (2000) The future of the community mental health team. International Review of Psychiatry, 12, 219 225 .

P.Tyrer Imperial College School of Medicine Paterson Centre, 20 South Wharf Road, London W2 IPD, UK

S. Simmonds Department of Public Health BKCW Health Authority, London, UK

J. Coid Forensic Psychiatry Research Unit, St Bartholomew's Hospital, London, UK

S. Mariott, P. Joseph Paterson Centre, London, UK

\section{Evidence-based psychiatry within multi-disciplinary clinical teams}

The paper by Lawrie et al (2001) and letter by Jha (2001) are of considerable interest and importance. The decision by the Royal College of Psychiatrists to introduce the Critical Review Paper as part of the MRCPsych Part II examination stimulated the Psychiatric Tutor and Trust Librarian of Barnet Community Healthcare NHS Trust (now part of Barnet, Enfield and Haringey Mental Health Trust and Barnet Primary Care Trust) to seek funding for posts of clinical librarians. Thames Postgraduate Medical and Dental Education (now the London Deanery) and the North London Consortium for Multiprofessional Education (now the North London Confederation for Workforce Development) agreed to provide funding for 1.5 whole-time equivalent clinical librarians and equipment to support this proposal, over a period of 30 months.

The clinical librarians work with 14 multi-disciplinary clinical teams within the Trust. Arrangements differ from team to team but in all cases the clinical librarians visit the teams at their place of clinical work. Priority is given to quick provision of information to clinicians in relation to questions arising out of direct patient contact. Portable information (lap-top computers and CDs) and communication (mobile telephones) technology is used to support this project. All disciplines, not just doctors, are encouraged to make use of this service. The clinical librarians have trained clinical team members to formulate focused clinical questions, use the internet for work and search a collection of databases. Training on critical appraisal is being considered at present.

Trusts have a responsibility to support evidence-based clinical practice by consultants and other members of the multidisciplinary team. Arguably, a clinical librarian/clinical information specialist should be a new member of the multidisciplinary mental health team, in the same way that the psychologist, community occupational therapist, the secretary, the manager and others are. The addition of such a member to the team will greatly facilitate mastery of critical appraisal and other evidence-based clinical practice skills, through the routine use and continuous improvement of such skills.

Jha, A. (200I) Evidence-based psychiatry (letter) British Journal of Psychiatry, 178, 575-576. 
Lawrie, S. M., Scott, A. I. F. \& Sharpe, M. C. (200I) Implementing evidence-based psychiatry: whose responsibility? British Journal of Psychiatry, 178, 195-196.

G. Ikkos Postgraduate Centre, Edgware Community Hospital, Edgware Middlesex HA8 OAD, UK

\section{Methodological rigour in cross-cultural research}

The paper by Selten et al (2001) is of interest in the context of methodological developments in cross-cultural research which now demand a much greater level of rigour in defining racial ethnic or cultural groups to reflect the hypotheses and the interpretation of the data (McKenzie et al, 1996). One of the difficulties of international work is that each country tends to use particular labels for particular ethnic and cultural groups which reflects a country's particular experience of migration and immigration. Specifically, the term Hindustanis as used by Selten $e t$ al is not meaningful. Hindustanis refers to people of Hindu origin, a religious category. This group is compared with Turkish and Moroccans - national categories reflecting place of birth. Alternatively, Hindustanis might refer to people of Indian origin, whom Selten et al and perhaps other researchers in The Netherlands, generally might refer to as Hindustanis. To justify the use of the term Hindustanis they suggest that British Indians migrated to The Netherlands in the 19th century. Selten et al are suggesting that people retain all the risk factors and cultural beliefs that determine illness behaviour despite exposure to new cultures and that these patterns persist over generations. This is simply not the case. It would have been of more interest to explore specific social factors that might account for their findings while taking account of the specific experiences of the cultural and sub-cultural groups that were more uniformly identified. For example, the ethnic density of each of their groups in comparison to the host population may explain the rates of psychosis (Bhugra \& Jones, 2001). Social factors such as cultural identity, unemployment and separation from parents may also explain variations in rates (Bhugra et al, 1997). These factors are entirely unexplored. The use of aggregated ethnic, religious or national groups that do not relate to similar groups makes any explanation or interpretation of their findings impossible, so reinforcing the view that research on ethnic groups bears no relationship to improving service delivery or understanding distress.

Bhugra, D., Leff, J., Mallett, R., et al (1997) Incidence and outcome of schizophrenia in Whites, AfricanCaribbeans and Asians in London. Psychological Medicine, 27, 791-798.

_ \& Jones, P. (200I) Migration and mental illness. Advances in Psychiatric Treatment, 7, 208-222.

McKenzie, K., Crowcroft, N. S., De Bono, D., et al (1996) Describing race, ethnicity, and culture in medical research. BM], 312, 1054-1060.

Selten, J. P., Veen, N., Feller, W., et al (200I) Incidence of psychotic disorders in immigrant groups to The Netherlands. British Journal of Psychiatry, 178, 367-372.

K. Bhui St Bartholomew's \& The Royal London School of Medicine and Dentistry, Department of Psychiatry, Basic Medical Sciences Building, Queen Mary \& Westfield College, Mile End Road, London El 4NS, UK

D. Bhugra Institute of Psychiatry, London, UK

Author's reply: Drs Bhui \& Bhugra write that categories are confused by comparing Turkish and Moroccan people with Hindustanis. However, it is perfectly clear from the text and the tables that people were classified by country of birth (or country of birth of the parents) and that immigrants from Turkey or Morocco were compared with immigrants from (the country of) Surinam.

We defined Hindustanis as people who migrated in the 19th century from British India to Surinam (not to The Netherlands, as Drs Bhui \& Bhugra suggest). In The Netherlands, the designation Hindustani is not a religious category and small proportions are Muslim or Buddhist.

Drs Bhui and Bhugra note that social factors, such as ethnic density, cultural identity, unemployment and separation from parents, are "entirely unexplored". Apparently, it escaped their attention that the proportions of children growing up in single-parent families were presented on p. 367 (Selten $e t$ al, 2001). This proportion is lowest for the group with the highest schizophrenia risk (Moroccans). Similarly, the pattern of unemployment rates (higher for Turkish and Moroccan people than for Surinamese or Antilleans) does not resemble the pattern of schizophrenia rates (lowest for Turkish people) (Selten \& Sijben, 1994). It follows that an explanation in terms of social factors is not as easy as suggested.

Drs Bhui and Bhugra correctly argue that attention should be paid to ethnic differences. Our study reported an increased incidence of schizophrenia among Surinamese citizens of The Hague, mostly Hindustanis. One might ask, therefore, whether the increased incidence also applies to African Surinamese immigrants, who have common origins with AfricanCaribbeans in the UK. An answer can perhaps be found indirectly. When they migrated to The Netherlands in the 1970s and early 1980s, Hindustanis and African Surinamese differed greatly in their preference for a Dutch residence. As a result, the ethnic composition of the Surinamese community in Amsterdam (70\% African and $26 \%$ Hindustani) is different from that in The Hague (10\% African and $80 \%$ Hindustani) (Martens \& Verweij, 1997). The Dutch psychiatric registry gave information on the residence of Surinamese-born people who had been discharged with an ICD diagnosis of schizophrenia in the period 1978-1996. The Central Bureau for Statistics provided figures for the Surinameseborn populations in Amsterdam and The Hague on 1 January 1990 (mid-period). The age structures of both populations were very similar. The results can be summarised as follows. In The Hague: 23815 (Surinamese-born) citizens in 1990; 253 citizens admitted over the 19-year period. In Amsterdam: 38722 (Surinamese-born) citizens in 1990; 493 admitted. These results although not definitive, suggest that the incidence of schizophrenia is also increased for African Surinamese immigrants. This conclusion is supported by clinical experience and a small incidence study in Amsterdam (Dekker et al, 1996).

Dekker, J., Peen, J., Heijnen, H., et al (1996) Psychiatric admissions in Amsterdam by ethnicity and diagnosis (in Dutch). Nederlands Tijdschrift voor Geneeskunde, 140, 368-37I.

Martens, E. P. \& Verweij, A. O. (1997) Surinamese in the Netherlands. Rotterdam: Institute for SocioEconomic Research.

Selten, J. P. \& Sijben, N. (1994) First admission rates for schizophrenia in immigrants to the Netherlands. Social Psychiatry and Psychiatric Epidemiology, 29, 7I-77.

_, Veen, N., Feller, W., et al (200I) Incidence of psychotic disorders in immigrant groups to The Netherlands. British Journal of Psychiatry, I78, 367-372.

J. P. Selten Department of Psychiatry, University Medical Centre, PO Box 85500, 3508 GA Utrecht, The Netherlands 